\title{
THE ASSESSMENT OF TUBERCULOSIS IN PATIENTS WITH INFLAMMATORY RHEUMATIC DISEASES TREATED WITH BLOCKERS OF THE TUMORAL NECROSIS ALPHA FACTOR: A RETROSPECTIVE OBSERVATIONAL MULTICENTRE STUDY
}

Ileana Filipescu', Sorana D. Bolboaca ${ }^{2}$, Doina Baltariu ${ }^{3}$, Liana Chicea $^{4}$, Adriana Ciornohuz ${ }^{5}$, Bianca Comsa $^{6}$, Laura Damian', Daniela Dragomir ${ }^{7}$, Simona Falaus ${ }^{6}$, Ioana Felea ${ }^{1}$, Gabriela Ieremia ${ }^{8}$, C. Marinescu ${ }^{1}$, Minodora Mihai ${ }^{9}$, Eugenia Mociran ${ }^{8}$, Laura Muntean', Liana Muresan ${ }^{10}$, C. Nedelcut ${ }^{1}$, D. Paduraru ${ }^{5}$, Cristina Pamfil${ }^{1}$, Nadia Radics ${ }^{11}$, Elena Rezus ${ }^{5}$, Simon Siao-Pin ${ }^{1}$, Cristina Tacu ${ }^{5}$, Maria-Magdalena Tamas ${ }^{1}$, Maria Vaida Voievod ${ }^{12}$, Mihaela Nicola Velcherean ${ }^{13}$, Adriana Voie ${ }^{8}$, Simona Rednic ${ }^{1}$

${ }^{1}$ Department of Rheumatology, Iuliu Hatieganu University of Medicine and Pharmacy, Cluj-Napoca

${ }^{2}$ Department of Medical Informatics and Biostatistics,

Iuliu Hatieganu University of Medicine and Pharmacy, Cluj-Napoca; ${ }^{3}$ Military Hospital Cluj-Napoca;

${ }^{4}$ V. Papilian Faculty of Medicine Sibiu; ${ }^{5}$ Rehabilitation Hospital, Iasi

${ }^{6}$ Salvosan Ciobanca Hospital, Zalau; ${ }^{7}$ Municipal Hospital, Timisoara

${ }^{8}$ Emergency Hospital, Baia Mare; ${ }^{9}$ ASTRA Clinic, Sibiu

${ }^{10}$ Town Hospital Dr. G. Trifon, Bistrita Nasaud; ${ }^{11}$ County Hospital, Turda

${ }^{12}$ Municipal Hospital, Arad; ${ }^{13}$ County Hospital, Deva

\begin{abstract}
Aim. To achieve extensive information (regional) in relation with the tuberculosis identified in current clinical practice in patients with inflammatory rheumatic diseases treated with biological agents.

Patients and methods. Twenty seven rheumatologists from 11 Romanian medicale center agreed to participate voluntarily and provide required data on tuberculosis (TB) occurring between January 1999 and June 2011 in their patients with rheumatoid arthritis (RA), ankylosing spondylitis (AS) and psoriatic arthropathy (PsA) in relation with anti-TNFa agent. This observational research included 693 patients (RA $n=492, S A n=137, A P n=64)$. All patients were screen for latent Mycobacterium tuberculosis infection (LTBI) before they start anti-TNFa treatment. Chemoprophylaxis with isoniazid before anti-TNFa therapy is recommended if the diameter of tuberculin skin test reaction is more than $5 \mathrm{~mm}$ (before 2005 only if indurations was more than $10 \mathrm{~mm}$ ). We recorded the demographic characteristics, and complex information about disease, treatment, tuberculosis diagnosis and the comorbidities. Incidence rate of TB are presented as events $/ 1,000$ person-years with associated $95 \%$ confidence interval $[95 \% \mathrm{Cl}]$.

Results. Fifteen patients were diagnosed with TB, most (60\%) were born in rural areas and $40 \%$ in areas with higher incidence $(\geq 80 \%, 000)$ of TB. The incidence of TB was $1.65 \%$ (IC95\% [11.54-34.63]). The extra pulmonary sites were present in $53.3 \%$ of the cases. Cultures were positive for Mycobacterium tuberculosis in 11 cases (73.3\%). Suspicion of TB was confirmed histological in 6 cases (40\%). The average duration of developing TB after initiation of TNF inhibitor was 23.26 months (range one month to 120 months). In 7/12 TB cases treated with IFX the incidence appeared in the first year of treatment. Any of known risk factors don't have a significant influence in our cohort.

Conclusions. The risk of reactivation of a latent TB during biologic therapy is greater in patients with rheumatic inflammatory diseases living in geographical areas with high endemicity of TB infection. Reduced compliance to chemoprophylaxis may be responsible for the occurrence of these cases.
\end{abstract}

Keywords: tuberculosis, rheumatoid arthritis, ankylosing spondylitis, psoriatic arthropathy, anti TNFa-agent

Correspondence address:

Ileana Filipescu, MD, Rheumatology Clinic, Iuliu Hatieganu University of Medicine and Pharmacy, 2-4 Clinicilor Street,

400006 Cluj-Napoca, Romania

E-mail: ileana_nicoara@yahoo.com 


\section{INTRODUCTION}

The TNF $\alpha$ is a pro-inflammatory cytokine produced by macrophages and it is the common ground for many rheumatologic diseases, amongst which rheumatoid arthritis (RA), psoriatic arthropathy (PsA) and ankylosing spondylitis (AS) are the most studied (1). Most results referring to tuberculosis (TB) incidence are coming from research with RA patients. There is few data in the literature referring to the occurrence of this specific infection in patients with different inflammatory rheumatic disorders that had the anti-TNF $\alpha$ therapy as an extra risk factor. Tubach coordinated a retrospective study on patients with multiple inflammatory diseases included in the RATIO registry; they had in common the anti-TNF $\alpha$ treatment (2).

Amongst the EULAR recommendations on the way the adverse reactions should be collected and reported, there is also the importance of achieving extensive regional or local data, where national reporting is not possible (3). In this way possible errors given by specific characteristics of the patients can be avoided.

The aim of our study was to evaluate the rate of TB in patients with RA, AS and PsA receiving biological therapy with anti-TNF $\alpha$ agent in daily practice. The secondary objectives were to identify the risk factors and to assess the evolution of the cases.

\section{METHODS}

This observational retrospective study was conducted in 11 medical centers in Romania and included all patients with RA, AS and PsA which received at least one TNF $\alpha$ blocker (infliximab-IFX, etanercept-ETA or adalimumab-ADA) between January 1999 and June 2011. These patients were following the treatment recommended by the rheumatologist according to the national protocol $(4,5)$. There were 27 rheumatologists who agreed to voluntarily participate in this study and who provided information related to the TB infections occurring during the biological anti-TNF $\alpha$ therapy of their patients. Each medical center also collected the following data: demographic factors, total number of patients with RA, AS and PsA undergoing biological therapy, duration of the treatment for each of the three biological agents that were given to the patients.

The study protocol was approved by the Ethics Committee of the "Iuliu Hatieganu" University of Medicine and Pharmacy from Cluj-Napoca. We obtained the written informed consent from all patients.

\section{STATISTICAL ANALYSIS}

Based on these report forms, we created afterwards a database to be used for further processing of the items. Quantitative variables were summarized by median and interquartile range (first and third quartiles) for variables that have been shown not to be normally distributed, or as mean and standard deviation for normally distributed data. Qualitative variables were summarized by absolute and relative frequencies (\%) with associated $95 \%$ confidence interval calculated under assumption of binomial distribution (6). For more accurately reporting incidence of TB we used the TB/1,000 patient-years index. This index was calculated for each anti-TNF $\alpha$ agent, for each of the three diseases. The identifying of risk factors was tested using logistic regression. Data analysis was conducted with Statistic program (v. 8.0) at a significance level of 5\%.

\section{RESULTS}

\section{The characteristics of the cohort}

The main characteristics of the 693 patients who met the criteria for inclusion in the study are shown in Table 1.

TABLE 1. The main characteristics of the study patients

\begin{tabular}{|l|c|c|c|}
\hline & $\begin{array}{c}\text { Rheumatoid } \\
\text { arthritis } \\
(\mathrm{n}=492)\end{array}$ & $\begin{array}{c}\text { Ankylosing } \\
\text { spondylitis } \\
(\mathrm{n}=137)\end{array}$ & $\begin{array}{c}\text { Psoriatic } \\
\text { arthritis } \\
(\mathrm{n}=64)\end{array}$ \\
\hline Age (years) & $52(16-76)$ & $38(18-56)$ & $42(20-67)$ \\
\hline Female, $\mathrm{n}(\%)$ & $405(82.3)$ & $20(14.6)$ & $38(59.4)$ \\
\hline Anti-TNFa agent & & & \\
Infliximab, $\mathrm{n}(\%)$ & $276(56.1)$ & $64(46.7)$ & $35(54.7)$ \\
Etanercept, $\mathrm{n}(\%)$ & $164(33.3)$ & $48(35.0)$ & $23(35.9)$ \\
Adalimumab, $\mathrm{n}(\%)$ & $52(10.6)$ & $25(18.2)$ & $6(9.4)$ \\
\hline
\end{tabular}

Results are expressed as mean (limits) or $\mathrm{n}(\%), \mathrm{TNF} \alpha=$ tumour necrosis factor $\alpha$

The studied cohort was mainly formed of patients with RA (71\%) with a mean age of 52 years (with limits between 19 and 76). The percentage of patients having AS was $19.8 \%$ and those with PsA was $9.2 \%$. Out of the total 693 patients included in the study $66.8 \%$ were women. Analyzing the gender distribution in the three groups, it could be noticed that women were the majority among patients diagnosed with RA and PSA, while $85.4 \%$ of those with AS $(n=137)$ were men.

Of the total number of 693 patients, more than a half $(55 \%)$ was following therapy with IFX. The percentage of patients treated with ETA and ADA was $34 \%$ and $11 \%$, respectively. In the group of pa- 
tients with AS ( $\mathrm{n}=137), 53 \%$ were using one of the TNF $\alpha$-blockers with subcutaneous administration (ETA or ADA), while more than half of those with RA and of those with PsA were undergoing an infusion with IFX.

In this research 15 patients were diagnosed with TB. The general characteristics of these cases are presented in Table 2.

Two patients had concomitant renal disease and other four subjects used corticotherapy $\geq 10 \mathrm{mg} /$ daily, for more than one year.

\section{The history of latent TB}

Tuberculin skin reaction diameter was $>10 \mathrm{~mm}$ in 3 patients $(20 \%)$, between $5-10 \mathrm{~mm}$ in 4 cases $(26.67 \%)$ and $<5 \mathrm{~mm}$ in 8 patients $(53.33 \%)$.

Chemoprophylaxis was performed prior to initiation biology only in three patients. In four cases of TB occurred in patients with IDR between 5 and 8 $\mathrm{mm}$. Those patients did not undergo chemoprophylaxis properly as recommended.

Lung scans performed prior to initiating biological therapy were normal in all patients who subsequently developed TB. None of the subjects had a personal history of TB, most (60\%) were born in rural areas and $40 \%$ in areas with higher incidence ( $\geq 80 \%$ oоo) of TB.

\section{The method of diagnosing and the localisation of TB cases}

Pulmonary TB was seen in 7 patients $(46.6 \%)$, in other three cases $(20 \%)$ the lymph node was the location. In $33.3 \%(\mathrm{n}=5)$ of subjects, it was disseminated (peritoneum, meninges).

The cultures were positive for Mycobacterium tuberculosis in 11 cases $(73.3 \%)$. Suspicion of TB was histological confirmed in six cases $(40 \%)$, in other two cases the diagnosis of TB was based on the suggestive imaging (radiography and CT).

\section{The therapeutic attitude}

All patients diagnosed with tuberculosis medication stopped biological treatment and followed the recommendations of the specialist in TB treatment (in accordance with the national program for the prevention and treatment of tuberculosis) (7). One patient with miliary TB died in an intensive care unit. After completion of TB treatment, RA therapy was resumed, but with another biological agent - rituximab. This treatment was recommended after 12.4 months (range between 9 and 22 months) in 5 patients. No relapse of TB was recorded.

TABLE 2. The characteristics of the 15 TB cases

\begin{tabular}{|c|c|c|c|c|c|c|c|c|c|}
\hline Subject & Gender & Age & Disease & $\begin{array}{l}\text { Biological } \\
\text { agent }\end{array}$ & $\begin{array}{c}\text { Disease } \\
\text { duration (year) }\end{array}$ & $\begin{array}{c}\text { Biological } \\
\text { duration (months) }\end{array}$ & TST (mm) & Prophylaxis & TB sites \\
\hline 1. & $\mathrm{~F}$ & 60 & RA & IFX & 3.2 & 1 & 0 & NO & pulmonary \\
\hline 2. & M & 56 & PSA & IFX & 9.3 & 2 & 3 & NO & pulmonary \\
\hline 3. & $M$ & 27 & AS & IFX & 5.2 & 3 & 16 & YES & pulmonary \\
\hline 4. & M & 42 & RA & IFX & 13.1 & 6 & 0 & NO & peritoneum \\
\hline 5. & $M$ & 57 & PSA & IFX & 4.6 & 6 & 20 & YES & pulmonary \\
\hline 6. & $\mathrm{~F}$ & 65 & RA & IFX & 14.6 & 11 & 3 & NO & pulmonary \\
\hline 7. & M & 47 & AS & IFX & 9.7 & 12 & 0 & NO & pulmonary \\
\hline 8. & M & 46 & AS & ETA & 27.2 & 12 & 16 & YES & pulmonary \\
\hline 9. & $\mathrm{~F}$ & 65 & RA & IFX & 6.8 & 15 & 8 & NO & lymph node \\
\hline 10. & M & 46 & PSA & IFX & 12.1 & 19 & 8 & NO & lymph node \\
\hline 11. & $\mathrm{~F}$ & 59 & RA & ADA & 5 & 20 & 6 & NO & peritoneum \\
\hline 12. & M & 55 & AS & ADA & 11.4 & 26 & 5 & NO & peritoneum \\
\hline 13. & $F$ & 54 & RA & IFX & 10 & 36 & 0 & NO & lymph node \\
\hline 14. & $\mathrm{~F}$ & 63 & RA & IFX & 16 & 60 & 0 & NO & peritoneum \\
\hline 15. & $\mathrm{~F}$ & 72 & RA & IFX & 12.1 & 120 & 3 & NO & meninges \\
\hline
\end{tabular}

$\mathrm{F}=$ female, $\mathrm{M}=$ male, $\mathrm{RA}=$ Rheumatoid Arthritis, $\mathrm{AS}=$ Ankylosing Spondylitis, PsA=Psoriatic Arthritis, IFX=infliximab, $A D A=a d a l i m u m a b$, ETA=etanercept, TST= Tuberculin Skin Test 


\section{Temporal relationship with exposure to the biological treatment}

The TB cases appeared after a mean time of 23.26 months (range one month to 120 months) (Fig. 1). In $53.3 \%$ patients $(n=8)$ specific infection was diagnosed in the first year of biological therapy, $87.5 \%$ $(n=7)$ of them were treated with IFX.

\section{The connection between the biological agent, the rheumatic disease and TB}

TB incidence was 21.65\% [CI95\% (11.546; $34,630)$ ]. Most patients with TB $(n=14)$ had been treated with only one anti-TNF $\alpha$ agent. One patient with AS was diagnosed with TB after 26 months after the initiation of the second TNF $\alpha$ blocker, which was ADA. ETA has been involved in the development of a single case of TB in other patient with AS. In 8 patients TB was diagnosed in the first year, most of them $(87.5 \%)$ were treated with IFX.

Most TB cases $(n=8)$ occurred in patients with $\mathrm{RA}$, the biological therapy duration and the number of subjects was highest in this group (Table 3).

The number of TB cases/1,000 patient-years was $0.78 / 4.35 / 0.23$ for the three biological agents involved (IFX/ADA/ETA).

\section{DISCUSSION}

Mycobacterium tuberculosis is responsible for the occurrence of infection in $1 / 3$ of population and causes more than 2 million deaths annually (8).

This is the first study from Romania in which the incidence of TB in patients with various rheumatic
TABLE 3. The distribution of TB cases according to biological agents and rheumatic disease

\begin{tabular}{|l|c|c|c|}
\hline $\begin{array}{l}\text { Biological } \\
\text { agent }\end{array}$ & $\begin{array}{c}\text { Patient- } \\
\text { years* }\end{array}$ & $\begin{array}{c}\text { Number of } \\
\text { TB cases }\end{array}$ & $\begin{array}{c}\text { TB/1000 patient- } \\
\text { years [95\% CI] }\end{array}$ \\
\hline Rheumatoid arthritis \\
\hline Infliximab & 14302.82 & 7 & $0.49[0.13 ; 0.85]$ \\
\hline Etanercept & 4171.68 & 0 & 0 \\
\hline Adalimumab & 382.4 & 1 & $2.61[0.00 ; 7.74]$ \\
\hline Ankylosing spondylitis \\
\hline Infliximab & 369.42 & 2 & $5.41[0.00 ; 12.92]$ \\
\hline Etanercept & 89.77 & 1 & $11.13[0.00 ; 32.97]$ \\
\hline Adalimumab & 59.73 & 1 & $16.74[0.00 ; 49.56]$ \\
\hline Psoriatic arthritis & 618.03 & 3 & $4.85[0.00 ; 10.35]$ \\
\hline Infliximab & 80.48 & 0 & 0 \\
\hline Etanercept & 17.53 & 0 & 0 \\
\hline Adalimumab & & \\
\hline
\end{tabular}

*Patient-years index=patient number $\mathrm{X}$ biological treatment duration (years)

disorders who were treated with anti-TNF $\alpha$ therapy was evaluated. This research included subjects from the nine counties of the country with different incidence of TB reported in the general population.

In the last 50 years an increase in the incidence of severe infections in patients with RA has been noticed $(9,10)$. The results are inconsistent and vary by gender, ethnicity, and country. TB incidence among white women in America was of $1.2 \%$ ooo, compared with 5.8\%ooo, global incidence of TB (result includes men and all races, respectively (11). Anti-TNF $\alpha$ agents further increases this risk. TB incidence among American patients with RA and biological treatment was of $6.2 \%$ ооо (12).

The incidence of TB in people treated with anti$\mathrm{TNF} \alpha$ agents is assessed differently in different stud-

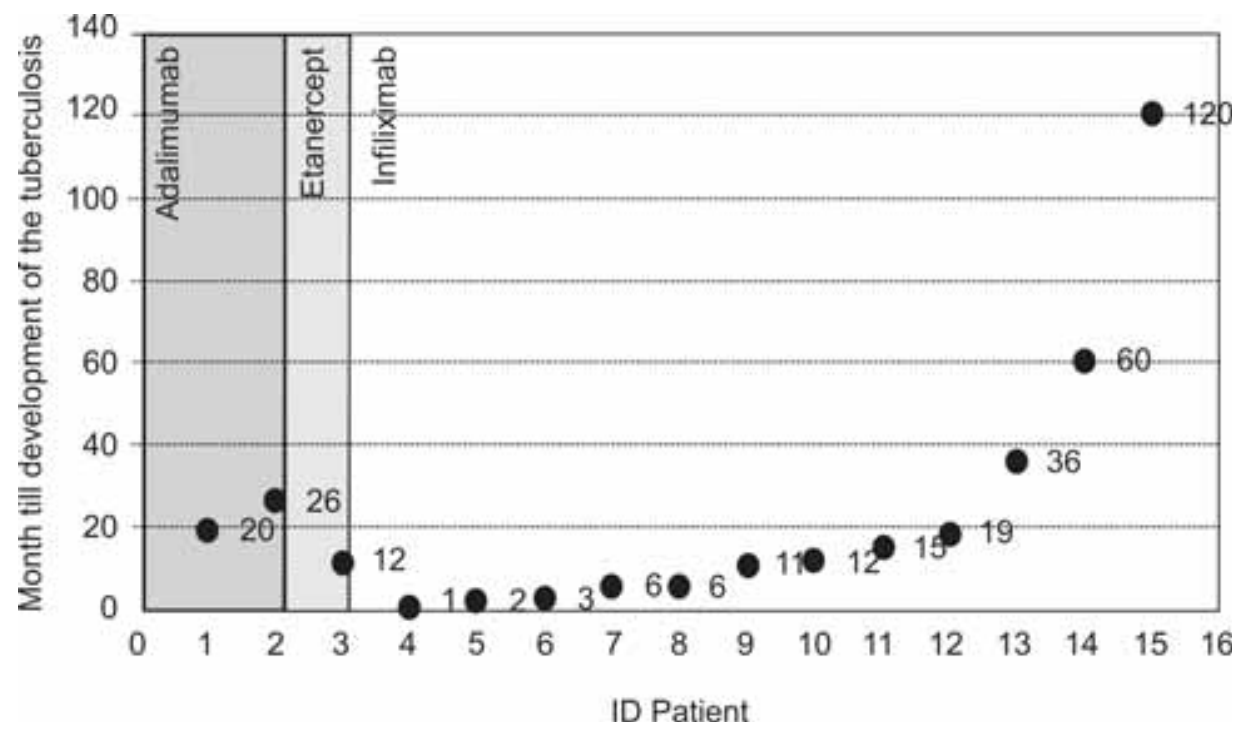

FIGURE 1. The temporal relationship between TB and biological agent 
ies, as follows: $54 \%$ oо in SUA, $383 \%$ оо in Spain, $187.5 \%$ оо in France, 8 cases at 456 patients in a study conducted in Portugal $(11,12)$.

Most data on the incidence of TB in patients treated with anti-TNF $\alpha$ agents come from developed countries with a relatively low incidence of infection. In Spain, a country considered to have a relatively high risk of TB, the incidence of this infection in patients with RA treated with TNF $\alpha$ inhibitors was 20 times higher than in the general population, and 7 times higher compared with the RA patients undergoing no biological treatment (13).

In our study 9 of the 15 cases with TB were from counties with a moderate and higher incidence. This results are sustained by the recent national data published by Cristea $\mathrm{C}$ in 2012 (14). The new cases of TB during 2010 in this counties were: 1,442 in Iasi, 876 in Arad, 696 in Maramures and 339 in Sibiu, most of them were in rural inhabitants $(54.4 \%)(14,15)$.

The data outline an overall picture of this disease in different regions of the country and are consistent with the reports from the literature, as the high prevalence of TB in the general population is a risk factor for new TB $(13,15,16)$.

In our country the highest incidence of TB is in the age range of 45-65 years (with an average of $107.0 \%$ and limits between $108.0 \%$ oo and $111.6 \%$ ooo). Most of our patients diagnosed with TB $(86.66 \%)$ are in this range, this being found in other studies as well $(14,15,17)$.

The risk of developing TB is increased in men (114.4\%ooo) compared to women $(52.9 \%$ oоo $)(14,15)$. In our cohort $53.33 \%$ of TB affected men.

Extrapulmonary localization was identified in $53.3 \%$ of the cases in our group. The data are consistent with the literature. In $\geq 50 \%$ of cases, localization was extrapulmonary, especially in Europe, in areas with higher prevalence of TB (18). Of the 70 cases of TB occurring secondary to the IFX therapy, $57 \%$ were extrapulmonary and $25 \%$ were disseminated, results come from the study of Keane (19). Extrapulmonary TB is 1-2 times more frequently, disseminated forms were found in a quarter of patients compared with immunocompetent individuals where the incidence is low $(<15 \%)(20)$.

Sustained corticosteroid therapy in a daily dose greater than $10 \mathrm{mg}$ of prednisone has been proven to increase 4 times the risk of severe infections and also of tuberculosis in the immunocompromised persons, the risk being proportional to given dose (13). Among independent risk factors described in other studies (corticosteroid therapy $\geq 10 \mathrm{mg}$ /day, other immunosuppressive agents, chronic debilitating diseases, alcoholism) none was significantly associated with the occurrence of tuberculosis in patients from our cohort.

To reduce the risk of developing TB in patients on biological therapy, starting with 2005 the UK guidelines recommended performing IDR prior to starting TNF $\alpha$ blockers therapy and the initiation of the chemoprophylaxis one month prior to the biological therapy in patients with IDR $\geq 5 \mathrm{~mm}$ (21).

Implementation of these recommendations has been performed in Romania since 2005. Of the 4 patients who developed TB in our cohort, one had an IDR of $5 \mathrm{~mm}$, other of 6 and 2 had $8 \mathrm{~mm}$ indurations, respectively, but due to reasons of non-compliance they did not correctly and completely follow the prophylactic treatment prior to initiating the biological treatment.

A strong argument in favor of initiation of chemoprophylaxis prior to the biological therapy is the study of Gomez (22). After starting mandatory chemoprophylaxis, the risk and incidence of TB in the Spanish population decreased proportionally with the compliance to screening from 41 cases of TB prior to 2002 , to 15 cases after mandatory administration of chemoprophylaxis. Only 2 cases of TB have been reported in patients with full compliance to prophylactic treatment, according to the same researchers (22). The risk of developing TB in patients treated with ADA decreased by $85 \%$ after initiation of active screening of latent infection, as it results from clinical trials conducted in Europe and North America (23). The results are consistent with those from the Swedish and British registries $(24,25)$.

To increase the detection rate of latent TB in patients with RA, QuantiFERON test was introduced in the requirements for candidates to TNF $\alpha$ inhibitors since 2010 (26). Our cases of TB occurred prior to this recommendation.

Although implementation in current practice of the recommendations from the British guidelines reduced the risk of occurrence of latent $\mathrm{TB}$, in countries with high prevalence of TB it is possible for primary tuberculosis to occur as a consequence of immunosuppression induced by the TNF $\alpha$ agents $(21,27)$. The PCR technique allows the identification of mycobacterium that caused TB infections (the first occult one) or of the overgrowth, but it cannot be done routinely in current practice. Therefore correct application of screening and prophylaxis measures is very important. 
In our cohort in most of the cases (53.3\%) Mycobacterium tuberculosis infection was diagnosed in the first year after starting biological treatment. This result is consistent with other reports in which $\mathrm{TB}$ occurs in the first year of anti-TNF $\alpha$ treatment, probably secondary to the reactivation of latent disease and not caused by an overgrowth $(10,16,28,29)$. Studies report differently this interval, in general IFX is responsible for the appearance of TB within 12 weeks after the initiation $(13,17,28)$. In the first 3 months of biological treatment, $72 \%$ of the cases of TB secondary to IFX were reported and only $28 \%$ in relation with ETA treatment (23). The average occurrence of TB after ETA is considered to be 6.5 months by Leonbruno and 11.5 months by Wallis $(30,31)$. TB was reported after 11 months of treatment with ADA (32). Recent studies have confirmed this pattern of occurrence of infection with Mycobacterium tuberculosis on average within 5.5 months of treatment with IFX, 13.4 months of treatment with ETA and 18.5 months with ADA, respectively $(1,30)$.

The correct identification of latent TB cases and appropriate chemoprophylaxis explain the extension of period in which TB occurred from 4 months to 12 months, especially in cases treated with monoclonal antibodies (25). In our cohort $87.5 \%$ of infections were diagnosed in the first year of treatment in patients treated with IFX, regardless of the disease.

The earliest and the frequent occurrence of TB in patients treated with IFX and ADA compared with ETA is a consequence of the different mechanisms of action. A possible explanation of this issue consists in the different ways of binding soluble TNF $\alpha$ and / or transmembranar. The three anti-TNF $\alpha$ agents appear to act differently with regard to the modulation of apoptosis and the production of IFN- $\gamma$, acting differently on the helper $\mathrm{T}$ cells and suppressor $\mathrm{T}$ cells $(1,19,20)$.

The monoclonal antibodies have a higher affinity and stability to the transmembranar receptor and also cause an increased penetration of the granuloma and increased apoptosis compared with soluble TNFR-p75 receptor blocker (20,33). Monoclonal antibodies have been responsible for the appearance of $\mathrm{TB}$ in most studies published in the literature $(26,27,28,29,30)$.

This issue has been confirmed by the results from the French RATIO registry, the risk of TB (SIR) was 18.6/29.3/1.8 for IFX/ADA/ETA (2).This pattern was encountered in our research. The index TB cases/1,000 patient-years was $0.78 / 4.35 / 0.23$ for the three preparations studied IFX/ADA/ETA.

Our research results should be interpreted with caution. Being a retrospective study, it is possible that some infections have not been reported and therefore tuberculosis occurring in patients treated with TNF $\alpha$ blockers is undervalued. Some demographics data of all patients evaluated were missing.

To conclude, most of the patients diagnosed with TB came from areas with moderate to increased incidence of the specific infection, rural residence predominating. The low adherence to chemoprophylaxis might be a cause of TB infection, regardless of the inflammatory pathology treated by the biological agents. Our study confirmed that anti-TNF $\alpha$ monoclonal antibodies (IFX and ADA) compared with p75 receptor inhibitor (ETA) are associated with a higher risk and earlier occurence of the TB infection.

\section{Acknowledgement}

The research activity of Dr.Ileana Filipescu was partially supported by the European Commission and by the Romanian Government through the project POSDRU/88/1.5/S/58965 „Doctoral Scholarships for increasing competitiveness in the medical and pharmaceutical field“. „Iuliu Hatieganu“ University of Medicine and Pharmacy Cluj-Napoca is a Partner institution in this Financial Contract.

3. Dixon W.G., Carmona L., Finckh A., et all. EULAR points to consider when establishing, analysing and reporting ASfety data of biologics registers in rheumatology. Ann Rheum Dis 2010; 69(9):1596-602.

4. Comisia de specialitate Reumatologie a Ministerului Sănătății 2010 Bolosiu H., lonescu R., Chirieac R., Georgescu L., Rednic S., Suta M., et al. Ghidul de tratament al poliartritei reumatoide. Revista Română De Reumatologie 2011; (1):36-53.

5. Protocoale terapeutice-Casa de Asigurări de Sănătate [online] [accesat ianuarie,10,2010]. Available from www.cnas.ro/ medicamente/protocoale-terapeutice' 
6. Jäntschi L., Bolboacă S.D. Exact Probabilities and Confidence Limits for Binomial ASmples: Applied to the Difference between Two Proportions. ScientificWorldJOURNAL 2010;10:865-878.

7. Ghid metodologic de implementare a programului national de control al tuberculozei 2007-2011. Institutul național de pneumologie "Marius Nasta" Bucuresti 2007 [online] [acceASt iunie/22/2011]. Available from: http://www.srp.ro/ProgramulNational-de-Control-al-Tuberculozei-118.htm

8. World Health Organization: „Global tuberculosis control: WHO report 2011", Geneva, World Health Organization, 2011, WHO/ HTM/TB/2011.16.

9. Solovic I., Sester M., Gomez-Reino J.J., et al. The risk of tuberculosis related to tumour necrosis factor antagonist therapies: a TBNET consensus statement. ERJ 2010;36(5):1185-206.

10. Muñoz L., Casas S., Juanola X., et al. Prevention of anti-tumor necrosis factor-associated tuberculosis: a 10-year longitudinal cohort study. Clin Infect Dis 2015; 60:349.

11. Mohan A.K., Coté T.R., Block J.A,. et al. Tuberculosis following the use of etanercept, a tumor necrosis factor inhibitor. Clin Infect Dis 2004; 39(3):295-9.

12. Listing J., Gerhold K., Zink A. The risk of infections associated with rheumatoid arthritis, with its comorbidity and treatment. Rheumatology 2013; 52(1): 53-61.

13. Dixon W.G., Hyrich K.L., Watson K.D., et al. Drug-specific risk of tuberculosis in patients with rheumatoid arthritis treated with anti-TNF therapy: results from the British Society for Rheumatology Biologics Register (BSRBR). Ann Rheum Dis 2010; 69:522-528.

14. Cristea C. Evoluția Tuberculozei în anii 1999 -2012 în România. [online] [accesat august/22/2015]. Available from: http://www.ccss. ro/public_html/sites/default/files//Evolutia Tuberculozei in anii 19992012 in Romania.pdf

15. Ibraim E., Cioran N., Cocei H. Tuberculoza, în continuare in atentie. Pneumologia 2012; 61(2):78-83.

16. Bellofiore B., Matarese A., Balato N., et al. Prevention of tuberculosis in patients taking tumor necrosis factor-alpha blockers. J Rheumatol 2009; 83:76-77.

17. Simard J.F., Arkema E.V., Sundstrom A., et al. Ten years with biologics: to whom do data on effectiveness and safety apply? Rheumatology 2011; 50 (1): 204-213.

18. Carmona L., Descalzo M.A., Perez-Pampin E., et al. All-cause and cause-specific mortality in rheumatoid arthritis are not greater than expected when treated with TNF antagonists. Ann Rheum Dis 2007; 66:680-5.

19. Keane J., Gershon S., Wise R.P., et al. Tuberculosis Associated with Infliximab, a Tumor Necrosis Factor a-Neutralizing Agent. N Engl J Med 2001; 345:1098-104.

20. Saag K.G., Teng G.G., Patkar N.M., et al. American College of Rheumatology 2008 recommendations for the use of nonbiologic and biologic disease-modifying antirheumatic drugs in rheumatoid arthritis. Arthritis Rheum 2008;59:762-784.

21. British Thoracic Society Standards of Care Committee. BTS recommendations for assessing risk and for managing
Mycobacterium tuberculosis infection and disease in patients due to start anti-TNF-a treatment. Thorax 2005; 60:800-805.

22. Gomez-Reino J.J., Carmona L., Valverde V.R., Mola E.M., BIOBADASER Group. Treatment of rheumatoid arthritis with tumor necrosis factor inhibitors may predispose to significant increase in tuberculosis risk: A multicenter active-surveillance report. Arthritis Rheum 2003; 48(8):2122-27.

23. Perez J.L., Kupper H., Spencer-Green G.T. Impact of screening for latent TB prior to initiation anti-TNF therapy in North America and Europe. Ann Rheum Dis 2005; 64(III): 86.

24. Wajdula J., Macpeek D., Lim S., et al. Incidence of tuberculosis is low in patients receiving etanercept therapy for the treatment of rheumatoid arthritis: results from a combined analysis of US and ex-US double-blind trials and their open label extensions. Ann Rheum Dis 2007; 66(suppl 2):195.

25. Askling J., Fored C.M., Brandt L., et al. Risk and case characteristics of tuberculosis in rheumatoid arthritis associated with tumor necrosis factor antagonists in Sweden. Arthritis Rheum 2005; 52:1986-92

26. Bejarano V., Conaghan P.G., Quinn M.A., et al. Benefits 8 years after a remission induction regime with an infliximab and methotrexate combination in early rheumatoid arthritis. Rheumatology 2010; 49:1971-1974.

27. Campbell L., Chen C., Bhagat S.S., et al. Risk of adverse events including serious infections in rheumatoid arthritis patients treated with tocilizumab: a systematic literature review and meta-analysis of randomized controlled trials. Rheumatology 2011; 50(3):552-562.

28. Filipescu I., Pamfil C., Dumitru B., et al. Tuberculosis: a real threat for patients on biologic treatment and a diagnostic challenge. Excelence in Rheumatology 2011; 50: Supllim 2, ii23.

29. Galloway J.B., Hyrich K.L., Mercer L.K., et al. Anti-TNF therapy is associated with an increased risk of serious infections in patients with rheumatoid arthritis especially in the first 6 months of treatment: updated results from the British Society for Rheumatology Biologics Register with special emphasis on risks in the elderly. Rheumatology 2010; 31:1-8.

30. Leobruno J.P., Einarson T.R., Keystone E.C., et al. The Safety of anti-tumour necrosis factor treatments in rheumatoid arthritis: meta and exposure-adjusted pooled analyses of serious adverse events. Ann Rheum Dis 2009; 68, 1136-1145.

31. Wallis R.S., Broder M.S., Wong J.Y., et al. Granulomatous Infections Due to Tumor Necrosis Factor Blockade: Correction Clin Infect Dis 2004; 39(8):1254-1255.

32. van de Putte L.B., Atkins C., Malaise M., et al. Efficacy and safety of adalimumab as monotherapy in patients with rheumatoid arthritis for whom previous disease modifying antirheumatic drug treatment has failed. Ann Rheum Dis 2004; 63:508-16.

33. Keane J. Tumor Necrosis Factor Blockers and Reactivation of Latent Tuberculosis Clin Infect Dis 2004; 39(3):300-302 